\title{
Ring-Opening Polymerization of Lactides by (Pyrazol-1-ylmethyl)pyridine Zn(II) and Cu(II) Complexes: Kinetics, Mechanism and Tacticity Studies
}

\author{
Stephen O. Ojwach ${ }^{*}$ and Thembisile P. Zaca \\ School of Chemistry and Physics, University of KwaZulu-Natal, Pietermaritzburg Campus, Private Bag X01 Scottsville, 3209 South Africa.
}

Received 31 March 2014, revised 3 September 2014, accepted 25 September 2014.

\begin{abstract}
The kinetics, mechanism and polymer microstructure studies of ring-opening polymerization (ROP) of lactides (LA) by Zn(II) and $\mathrm{Cu}(\mathrm{II})$ complexes of (pyrazolylmethyl)pyridine ligands, 2-(3,5-dimethylpyrazol-1-ylmethyl)pyridine (L1) and 2-(3,5-diphenylpyrazol-1-ylmethyl)pyridine (L2) is described. The complexes $\left[\mathrm{Zn}(\mathrm{Ac})_{2}(\mathrm{~L} 1)\right](1),\left[\mathrm{Cu}(\mathrm{Ac})_{2}(\mathrm{L1})\right](2),\left[\mathrm{Zn}(\mathrm{Ac})_{2}(\mathrm{L2})\right]$ (3) and $\left[\mathrm{Cu}_{2}(\mathrm{Ac})_{4}(\mathrm{~L} 2)_{2}\right]$ (4) form active initiators in the ROP of D,L-LA and L-LA monomers. Generally Zn(II) complexes 1 and 3 exhibit higher activities compared to the corresponding $\mathrm{Cu}(\mathrm{II})$ complexes 2 and 4 . Polymerization kinetics of D, L-LA show higher rates compared to the L-LA reactions. All the polymerization reactions follow pseudo first-order kinetics with respect to monomer while 1 shows second-order dependency on the polymerization reactions. Molecular weights of the polymers range from $813 \mathrm{~g} \mathrm{~mol}^{-1}$ to $9207 \mathrm{~g} \mathrm{~mol}^{-1}$ and exhibit relatively narrow molecular weight distributions between 1.2 to 1.6. While poly (D,L-LA) are predominantly atactic, poly(L-LA) are largely isotactic. All polymerization reactions proceed through coordination insertion mechanism followed by hydrolysis of the end groups.
\end{abstract}

KEYWORDS

Zinc and copper complexes, lactide, polymerization, kinetics, mechanism.

\section{Introduction}

Biopolymers derived from renewable resources have attracted growing attention over the last decades as biocompatible and biodegradable alternatives to petrochemical-based plastics. ${ }^{1-5}$ An excellent example of such a biodegradable polymer is polylactide (PLA), which can be obtained by ring-opening polymerization (ROP) of lactide monomers. PLAs display desirable mechanical, optical and chemical properties such as optical transparency, ease of processing and ease of microbial decomposition or degradation. Due to these unique features, PLAs have wide range of applications in food packaging ${ }^{6 a}$ as well as in pharmaceutical industries, tissue engineering and drug delivery devices. ${ }^{6 b, c}$

The ring-opening polymerization of lactides can be catalyzed by organometallic initiators, ${ }^{7}$ organocatalysts ${ }^{8}$ as well as enzymes. ${ }^{9}$ Organometallic-based catalysts have several advantages that include proper control of polymer stereo-regularity and molecular weight distribution. ${ }^{10-12}$ Furthermore, it is possible to carry out detailed kinetic and mechanistic studies of the polymerization reactions and gain fundamental knowledge on the effect of structure on catalyst activity and polymer microstructure..$^{13}$ Although tin(II) octanoate ${ }^{14}$ as well as several metal alkoxides ${ }^{15}$ are efficient catalysts in the ROP of lactides, design of well-defined catalysts that could produce PLAs with desirable molecular weight and polymer microstructure still remains a major challenge both in academia and in industry. One major drawback of most of these metal-based catalysts is their relative toxicity, which limits the application of the resultant PLAs in medical fields. ${ }^{6 c, d}$ In addition, the high cost of transition metal-based catalysts has dissuaded their industrial appeal.

To circumvent these two problems, numerous research groups

* To whom correspondence should be addressed. E-mail: ojwach@ukzn.ac.za are shifting towards inexpensive and less toxic metals such as calcium(II), ${ }^{16}$ magnesium(II) ${ }^{17}$ and zinc(II) ${ }^{18,19}$ We recently reported the use of pyrazolyl(methyl)pyridine $\mathrm{Zn}$ (II) and $\mathrm{Cu}(\mathrm{II})$ complexes in the ring-opening polymerization of $\varepsilon$-caprolactone..$^{20}$ In this current work, we explore the potential use of these breeds of complexes as initiators in the ROP of Mesolactide (D,L-LA) and L-LA monomers. Detailed kinetics, mechanistic and polymer microstructure studies have been performed in order to elucidate the effect of catalyst structure and nature of monomer on the polymerization behaviour of these complexes.

\section{Experimental}

\subsection{Materials}

All air-sensitive manipulations were performed under argon using standard Schlenk line techniques. The $\mathrm{Zn}$ (II) and $\mathrm{Cu}(\mathrm{II})$ complexes were prepared according to our published procedures. ${ }^{20}$ Toluene and hexane solvents were distilled and dried from sodium/benzophenone mixture while dichloromethane was distilled from phosphorous pentaoxide. The monomers, D,L-LA and L-LA were purchased from Sigma-Aldrich and used as received. NMR spectra were recorded on a Bruker Ultrashield 400 instrument at room temperature in $\mathrm{CDCl}_{3}\left({ }^{1} \mathrm{H}\right.$ at 400 and ${ }^{13} \mathrm{C}$ at $100 \mathrm{MHz}$ ). Mass spectrometry was recorded on a Waters Micromass LCT Premier Mass Spectrometer TOF with nano ACQUITY UPLC System. Gel permeation chromatography (GPC) analyses of the polymers were performed on a Waters $600 \mathrm{E}$ instrument.

\subsection{Polymerization of Lactides}

Ring-opening polymerization reactions were performed by introducing an appropriate amount of the complex, depending on the $[\mathrm{LA}]_{0} /[\mathrm{I}]$ ratio, in a Schlenk tube equipped with a magnetic 
stirrer under argon. LA $(1.44 \mathrm{~g}, 0.01 \mathrm{~mol})$ was then added and toluene $(2 \mathrm{~mL})$ was added to the Schlenk tube using a syringe and temperature was set at $110{ }^{\circ} \mathrm{C}$. Kinetic experiments were carried out by withdrawing samples at regular intervals (approx. $0.1 \mathrm{~mL}$ ) using a syringe and quickly quenched by rapid cooling into NMR tubes containing $\mathrm{CDCl}_{3}$ solvent. The quenched samples were analyzed by ${ }^{1} \mathrm{H}$ NMR spectroscopy for determination of polymerization of LA to PLA. The percentage conversion of $[\mathrm{PLA}]_{\mathrm{t}} /\left([\mathrm{LA}]_{\mathrm{t}}+[\mathrm{PLA}]_{\mathrm{t}}\right) \times 100$, where $[\mathrm{PLA}]_{\mathrm{t}}$ and $[\mathrm{LA}]_{t}$ are the concentrations of the polymer and LA monomer at time $t$, respectively, $\left([\mathrm{LA}]_{\mathrm{t}}+[\mathrm{PLA}]_{\mathrm{t}},=[\mathrm{LA}]_{0}\right)$, was evaluated by integration of the peaks for LA (5.0 ppm, OCH signal) and PLA (5.2 ppm, OCH signal) according to the equation $[\mathrm{PLA}] /\left([\mathrm{LA}]_{\mathrm{t}}+[\mathrm{PLA}]_{\mathrm{t}}\right)=$ $\mathrm{I}_{5.2} /\left(\mathrm{I}_{5.2}+\mathrm{I}_{5.0}\right)$ where $\mathrm{I}_{5.0}$ is the intensity of the LA monomer signal at $5.0 \mathrm{ppm}$, and $\mathrm{I}_{5.2}$ is the intensity of the PLA signal at $5.2 \mathrm{ppm}$ for the $\mathrm{OCH}$ protons. ${ }^{20}$ The observed rate constants, $k_{\text {obs }}$, were extracted from the slopes of the lines of best-fit of the plots of $\ln [\mathrm{LA}]_{0} /[\mathrm{LA}]_{\mathrm{t}} v s$ time. The polymers were purified by dissolving the crude products in $\mathrm{CH}_{2} \mathrm{Cl}_{2}$ followed by addition of cold methanol. A white precipitate was formed, which was isolated by filtration and dried to constant weight prior to analyses by NMR and GPC.

\section{Gel Permeation Chromatography (GPC) Analyses}

In a typical analysis, polymer samples were dissolved in 3,5-di-tert-butyl-4-hydroxytoluene (BHT) stabilized THF ( $2 \mathrm{mg} / \mathrm{ml})$. The sample solutions were filtered via syringe through $0.45 \mu \mathrm{m}$ nylon filters before analyses. The SEC instrument consists of a Waters 1515 isocratic HPLC pump, a Waters 717plus auto-sampler, Waters 600E system controller (run by Breeze Version 3.30 SPA) and a Waters in-line Degasser AF. A Waters 2414 differential refractometer was used at $30^{\circ} \mathrm{C}$ in series with a Waters 2487 dual wavelength absorbance UV/Vis detector operating at variable wavelengths. Tetrahydrofuran (THF, HPLC grade, stabilized with $0.125 \%$ BHT) was used as

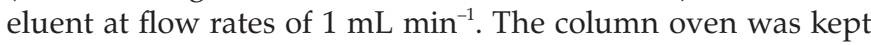
at $30^{\circ} \mathrm{C}$ and the injection volume was $100 \mu \mathrm{L}$. Two PLgel (Polymer Laboratories) $5 \mu \mathrm{m}$ Mixed-C $(300 \times 7.5 \mathrm{~mm})$ columns and a pre-column (PLgel $5 \mu \mathrm{m}$ Guard, $50 \times 7.5 \mathrm{~mm}$ ) were used. Calibration was done using narrow polystyrene standards ranging from 580 to $2 \times 10^{6} \mathrm{~g} \mathrm{~mol}^{-1}$. All molecular weights were reported as polystyrene equivalents and corrected by a factor of 0.58 .

\section{Results and Discussion}

\subsection{Ring-opening Polymerization of D,L-LA and L-LA Using} Complexes 1-4 as Initiators.

Initial screening of complexes 1-4 (Scheme 1) as initiators in the ring-opening polymerization (ROP) reactions of lactides were performed at $110{ }^{\circ} \mathrm{C}$ in toluene using $[\mathrm{M}] /[\mathrm{I}]$ ratio of 50 . All the complexes 1-4 were found to display appreciable catalytic activities giving conversions above $90 \%$ between $9-60 \mathrm{~h}$ (Fig. S1 in the online supplement). Having established the viability of 1-4 as catalysts in the ROP of D,L-LA and L-LA monomers, we performed detailed mechanistic and kinetics studies in order to understand the nature of the active species, influence of ligand motif and reaction conditions on catalyst activity and properties of the polymers obtained.

\subsection{Kinetics of LA Polymerization Reactions}

Kinetics of the polymerization reactions of lactide monomers catalyzed by complexes $1-4$ were followed using ${ }^{1} \mathrm{H}$ NMR spectroscopy. Table 1 gives a summary of the polymerization data. Plots of $\ln [\mathrm{LA}]_{\alpha} /[\mathrm{LA}]_{\mathrm{t}}$ vs. time for both monomers gave linear relationship consistent with a pseudo-first-order kinetics with respect to monomer for all the complexes (Fig. 1). The polymerization reactions thus follow simple pseudo-first-order kinetics with respect to lactide monomer as shown in Equation 1.

$$
\frac{d[\mathrm{LA}]}{-d t}=k[\mathrm{LA}]
$$

where $k=k_{p}[\mathrm{I}]^{\mathrm{x}}, k_{p}=$ rate of chain propagation and $\mathrm{I}=$ initiator; $x=$ order of reaction

From Fig. 1, the rate constants for $1-4$ were obtained as $0.328 \mathrm{~h}^{-1}$ (1), $0.066 \mathrm{~h}^{-1}(2), 0.196 \mathrm{~h}^{-1}(3)$ and $0.044 \mathrm{~h}^{-1}$ (4) for D,L-LA and $0.157 \mathrm{~h}^{-1}(\mathbf{1}), 0.074 \mathrm{~h}^{-1}(2), 0.107 \mathrm{~h}^{-1}(3)$ and $0.039 \mathrm{~h}^{-1}$ (4) for L-LA. The monomeric complex $\mathbf{1}$ was thus the most active while the dinuclear complex 4 was the least active. This trend contrasts our earlier reports where the binuclear complexes 3 and 4 were more active than their corresponding mononuclear analogues $\mathbf{1}$ and $2 .{ }^{20}$ Lower catalytic activities observed with increase in steric bulk of the pyrazolyl ligand in 1-4 could be largely apportioned to the steric crowding around the metal centre. Bridging acetate ligands in bimetallic complexes 3 and 4 could also play a role in blocking LA coordination to the active site hence lower activities. Mononuclear analogues $\mathbf{1}$ and $\mathbf{2}$ exhibit no such steric restric-

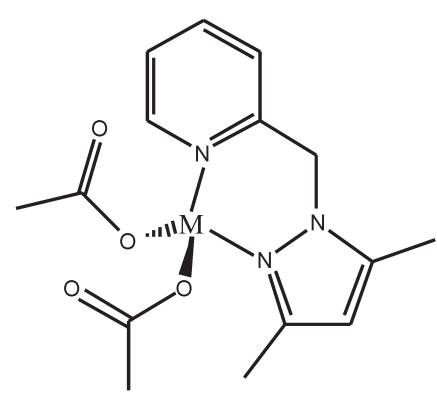

$\mathrm{M}=\mathrm{Zn}, \mathrm{R}=\mathrm{Me}(\mathbf{1})$ $\mathrm{M}=\mathrm{Cu}, \mathrm{R}=\mathrm{Me}(\mathbf{2})$

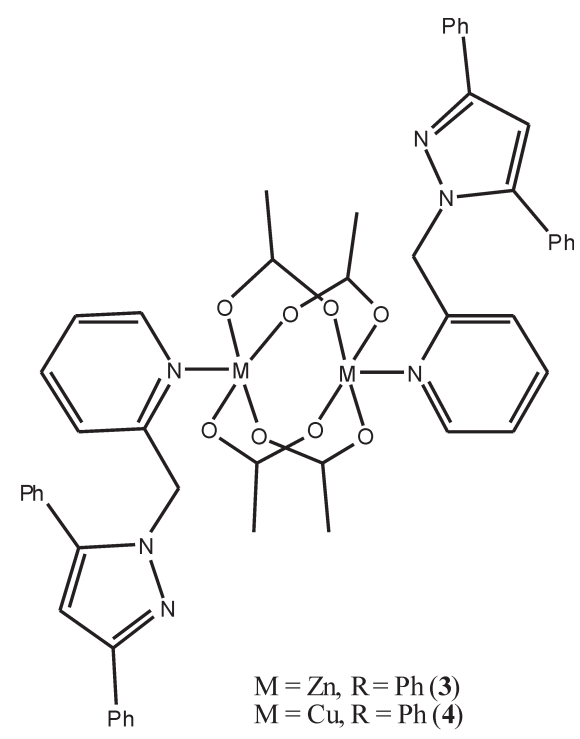

Scheme 1

Complexes employed as initiators in ROP of lactides. 
Table 1 Polymerization of D,L-LA and L-LA by complexes 1-4.

\begin{tabular}{cclrrrrrr}
\hline Entry & Initiator & Monomer & Time $/ \mathrm{h}$ & Conv $/ \%$ & $K_{\text {obs }} / \mathrm{h}^{-1}$ & $\mathrm{M}_{\mathrm{w}}{ }^{\mathrm{b}}$ & PDI $^{\mathrm{b}}$ & IE $^{\mathrm{c}}$ \\
\hline 1 & $\mathbf{1}$ & D,L-LA & 9 & 95 & 0.328 & 2381 & 1.64 & 0.35 \\
2 & $\mathbf{2}$ & D,L-LA & 54 & 96 & 0.066 & 940 & 1.23 & 0.14 \\
3 & $\mathbf{3}$ & D,L-LA & 28 & 99 & 0.196 & 2455 & 1.59 & 0.35 \\
4 & $\mathbf{4}$ & D,L-LA & 72 & 94 & 0.044 & 813 & 1.27 & 0.12 \\
5 & $\mathbf{1}$ & L-LA & 21 & 96 & 0.157 & 9081 & 1.12 & 1.33 \\
6 & $\mathbf{2}$ & L-LA & 54 & 95 & 0.074 & 3513 & 2.38 & 0.30 \\
7 & $\mathbf{3}$ & L-LA & 23 & 97 & 0.108 & 9207 & 1.19 & 1.40 \\
8 & $\mathbf{4}$ & L-LA & 60 & 90 & 0.039 & 3196 & 1.27 & 0.50 \\
\hline
\end{tabular}

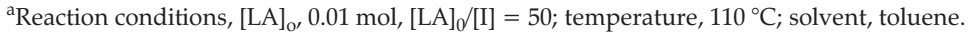

${ }^{\mathrm{b}}$ Determined by GPC relative to polystyrene standards, $\mathrm{Mw}_{(\exp )}=\mathrm{Mw}_{(\mathrm{GPC})} \times 0.58$ as correction factor.

${ }^{c}$ Initiator efficiency $(\mathrm{IE})=\mathrm{Mw}_{\text {exp }} / \mathrm{Mw}_{\text {calc }}$ where $\mathrm{Mw}_{\text {calc }}=\mathrm{Mw}_{(\text {monomer) }} \times[\mathrm{LA}]_{0} /[\mathrm{I}] \times\left[\mathrm{PDL} /[\mathrm{LA}]_{0}+\mathrm{Mw}_{\text {(chain-end groups) }}\right.$
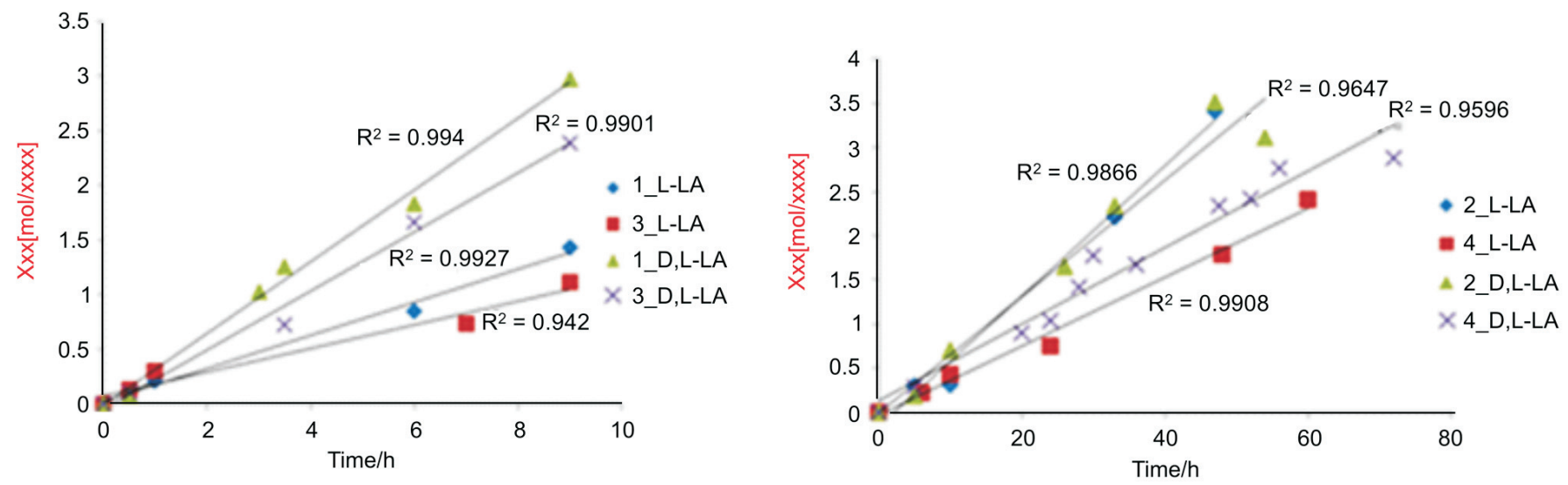

Figure 1 First-order kinetic plots of $\ln [\mathrm{LA}] \mathrm{o} /[\mathrm{LA}]_{\mathrm{t}} v s$ time for $1-4$ in the ring-opening polymerization of $\mathrm{D}, \mathrm{L}-\mathrm{LA}$ and $\mathrm{L}-\mathrm{LA}$ at $110^{\circ} \mathrm{C},[\mathrm{LA}]_{0}, 0.01 \mathrm{mmol}$ and $[\mathrm{LA}]_{0} /[\mathrm{I}]$ of 50 .

tions thus easier LA coordination to the metal centre. This observation is consistent with those of Carpentier and co-workers. ${ }^{21}$ Greater activities of $\mathrm{Zn}(\mathrm{II})$ initiators $\mathbf{1}$ and $\mathbf{3}$ in comparison to the $\mathrm{Cu}(\mathrm{II})$ catalysts 2 and 4 agree with literature reports. ${ }^{22}$

We also observed some influence of monomer stereochemistry on the kinetics of the polymerization reactions. As depicted in Table 1, higher rate constants were reported for D,L-LA compared to L-LA reactions. For example, using catalyst 1 , rate constants of $0.328 \mathrm{~h}^{-1}$ and $0.157 \mathrm{~h}^{-1}$ were obtained in the ROP of D, L-LA and L-LA monomers, respectively (Table 1, entries 1 and 5). Our findings are in tandem with recent reports by Buffet et $a .^{23}$ who reported $99 \%$ and $66 \%$ conversions for D,L-LA and L-LA monomers, respectively, under similar conditions. In general, rate constants observed for 1-4 were comparatively lower than most active initiators reported. ${ }^{24-26}$ For example, the mononuclear $\mathrm{Zn}$-alkoxide complex reported by Williams et al. ${ }^{24}$ considered to be one of the most active zinc catalyst, exhibits a rate constant of $0.002 \mathrm{~s}^{-1}$ in the polymerization of L-LA. Despite the relative low activities of $\mathbf{1 - 4}$, they were found to be more active than the aluminium alkoxide catalyst reported by Zhong et al..$^{27}$ which displays apparent rate constant of 0.902 day $^{-1}$ in the L-LA polymerization reactions.

\subsection{Order of Reaction With Respect to Initiator}

To assess the order of reaction with respect to initiator $\mathbf{1}$, the kinetics of the polymerization reactions were followed at different catalyst concentrations (Fig. S2) at constant D,L-LA monomer concentrations (Table 2 ). A plot of $\ln \left[k_{\text {obs }}\right]$ versus $\ln [1]$ produced a linear relationship consistent with pseudo-firstorder dependency of the reaction on [1] (Fig. 2). From the plot, the order of the reaction with respect to 1 was obtained as 2.32, indicative of a second-order dependency on $\mathbf{1}$. Fractional orders of the reaction with respect to initiator have been previously observed and are believed to arise from complicated aggregation of the active sites during polymerization reactions. ${ }^{28}$ Thus the overall rate law for D,L-LA polymerization by 1 can be represented as shown in equation 2. Attempts to determine the order of the reaction with respect to initiator 2 were unsuccessful due to longer induction periods which rendered the plots non-linear.

$$
\frac{d[\mathrm{LA}]}{-d t}=k[\mathrm{D}, \mathrm{L}-\mathrm{LA}][1]^{2,32}
$$

A linear plot of $k_{o b s}$ vs [1] (Fig. 3) exhibited a non-zero intercept suggesting a threshold catalyst concentration of $0.02 \mathrm{mM}$, below which polymerization would not occur..$^{29}$ William et al. ${ }^{24}$ reported threshold values of $0.7 \mathrm{mM}$ and $2.4 \mathrm{mM}$ at $25^{\circ} \mathrm{C}$ and $0{ }^{\circ} \mathrm{C}$, respectively, for the $\mathrm{Zn}$-alkoxide initiator. Our threshold concentration of $0.02 \mathrm{mM}$ at $110^{\circ} \mathrm{C}$ is thus significantly lower and could be apportioned to the relative thermal stability and tolerance to impurities of $\mathbf{1}$.

\subsection{Molecular Weight and Molecular Weight Distribution of Polylactides (PLA)}

The experimental and theoretical molecular weights and molecular weight distributions of the PLAs were determined by GPC and ${ }^{1} \mathrm{H}$ NMR spectroscopy, respectively (Tables 1 and 2). Low to moderate experimental molecular weights between $813 \mathrm{~g}$ $\mathrm{mol}^{-1}$ to $9207 \mathrm{~g} \mathrm{~mol}^{-1}$ were obtained. An interesting observation was the exceptionally high molecular weights of poly(L-LA) in comparison to poly(D,L-LA). For example, under similar condi- 


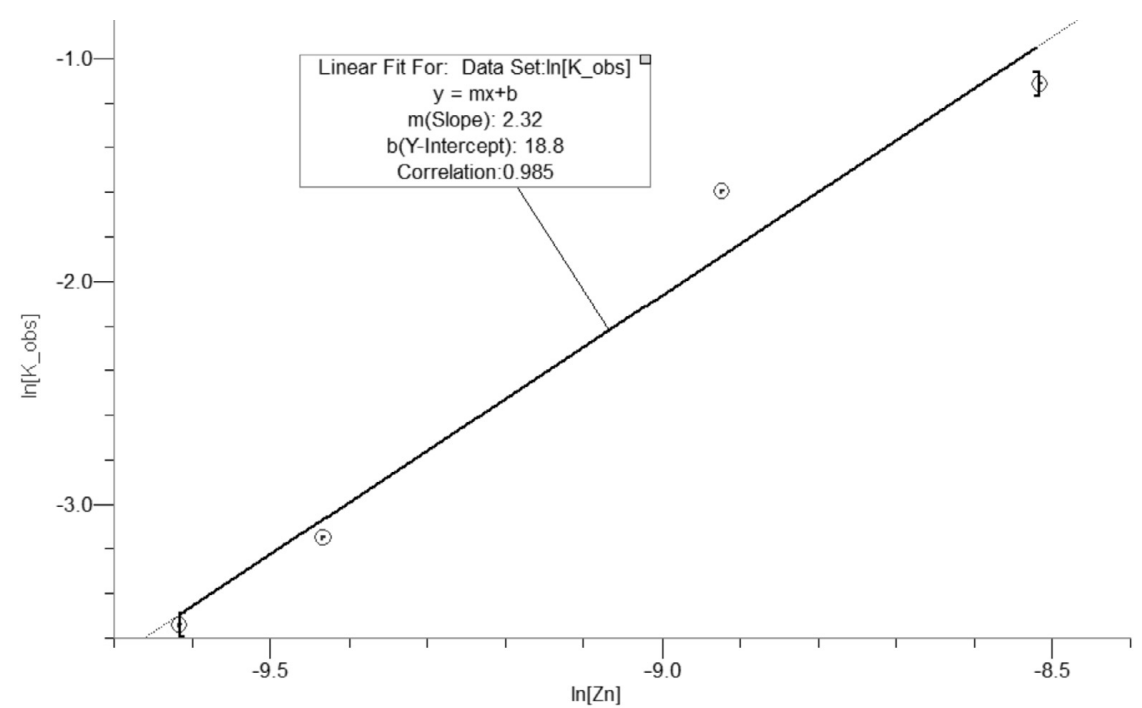

Figure 2 Linear plots of $\ln \left[k_{o b s}\right] v s \ln [1]$ in the polymerization of D,L-LA at $[\mathrm{D}, \mathrm{L}-\mathrm{LA}]_{0}=0.01 \mathrm{~mol}, 110{ }^{\circ} \mathrm{C}$ for the determination of order of reaction with respect to 1 .

tions, molecular weights of $9081 \mathrm{~g} \mathrm{~mol}^{-1}$ and $2381 \mathrm{~g} \mathrm{~mol}^{-1}$ were obtained for L-LA and D,L-LA monomers, respectively (Table 1, entries 1 and 5). Indeed the experimental Mw of PLA obtained from L-LA were above the theoretical Mw, exhibiting initiator efficiencies (IE) of about $133 \%$ compared to $35 \%$ in D,L-LA poly- merization reactions (Table 1 and Fig. 4). Reports of Buffet et al. ${ }^{30}$ sharply contrast our results as they recorded molecular weights of $18000 \mathrm{~g} \mathrm{~mol}^{-1}$ and $10750 \mathrm{~g} \mathrm{~mol}^{-1}$ for poly(D,L-LA) and poly(L-LA), respectively. Consistent with living polymerization behaviour, molecular weights increased with percentage con-

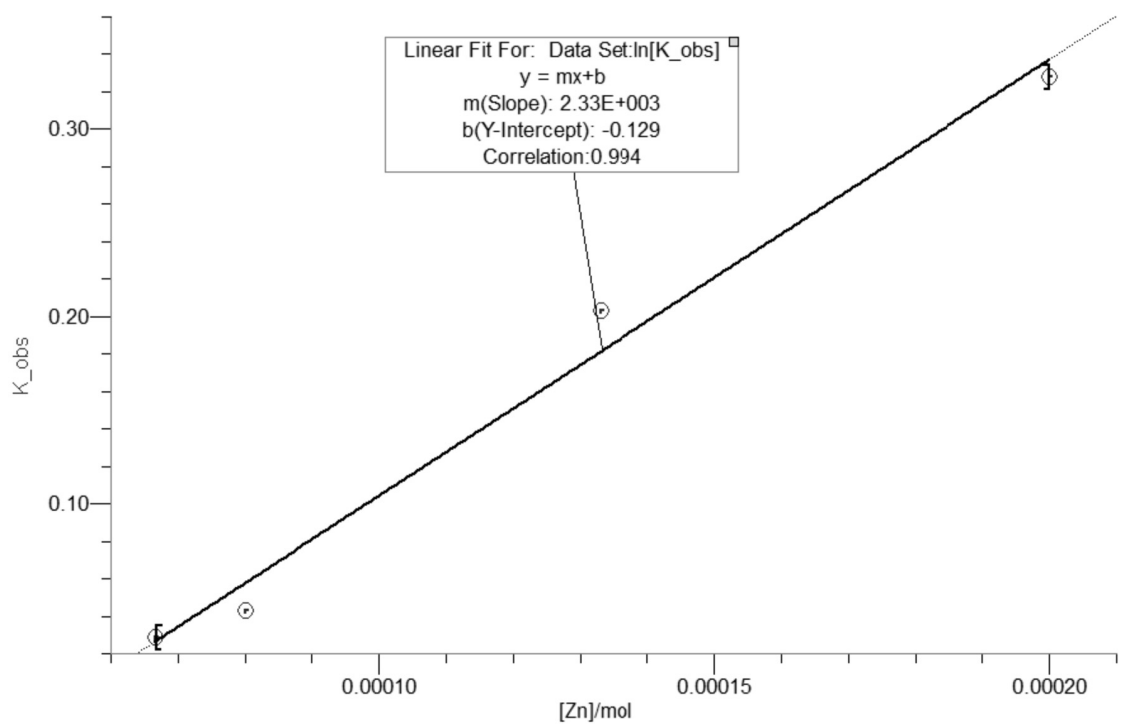

Figure 3 Plot of $k_{\mathrm{obs}} v s[1]$ for the polymerization kinetics of D,L-LA. Non-zero intercept at $\mathrm{x}=0.02 \mathrm{mM}$ corresponds to threshold catalyst concentration.

Table 2 Effect of reaction conditions on the polymerizations of D,L-LA and L-LA by 1.

\begin{tabular}{clccccccc}
\hline Code & Monomer & {$[\text { DLA }]_{0}[\mathrm{II}]$} & Time/h & Conv/\% & M $_{\mathrm{w}}{ }^{\mathrm{b}}$ & PDI $^{\mathrm{b}}$ & IE $^{\mathrm{c}}$ & \\
\hline 1 & L-LA & 50 & 1 & 20 & 1121 & 1.09 & 0.79 \\
2 & L-LA & 50 & 5 & 35 & 2622 & 1.18 & 1.04 & 1.28 \\
3 & L-LA & 50 & 7 & 50 & 4475 & 1.39 & 1.22 \\
4 & L-LA & 50 & 9 & 60 & 5072 & 1.52 & 1.10 \\
\\
5 & L-LA & 50 & 12 & 76 & 5767 & 1.43 & 1.33 \\
6 & L-LA & 50 & 20 & 96 & 9081 & 1.12 & 0.35 \\
7 & D,L-LA & 50 & 9 & 95 & 2381 & 1.64 & 0.15 \\
8 & D,L-LA & 100 & 24 & 98 & 2043 & 1.55 & 0.06 \\
\hline
\end{tabular}

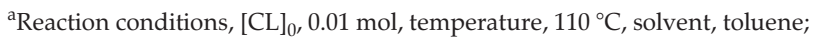

${ }^{\mathrm{b}}$ Determined by GPC relative to polystyrene standards, $\mathrm{Mw}_{(\exp )}=\mathrm{Mw}_{(\mathrm{GPC})} \times 0.58$ as correction factor.

${ }^{\mathrm{c}}$ Initiator efficiency (IE) $=\mathrm{Mw}_{\text {exp }} / \mathrm{Mw}_{\text {calc }}$ where $\mathrm{Mw}_{\text {calc }}=\mathrm{Mw}_{\text {(monomer) }} \times[\mathrm{LA}]_{0} /[\mathbf{1}] \times\left[\mathrm{PLA} /[\mathrm{LA}]_{0}+\mathrm{Mw}_{\text {(chain-end groups) }}\right.$. 


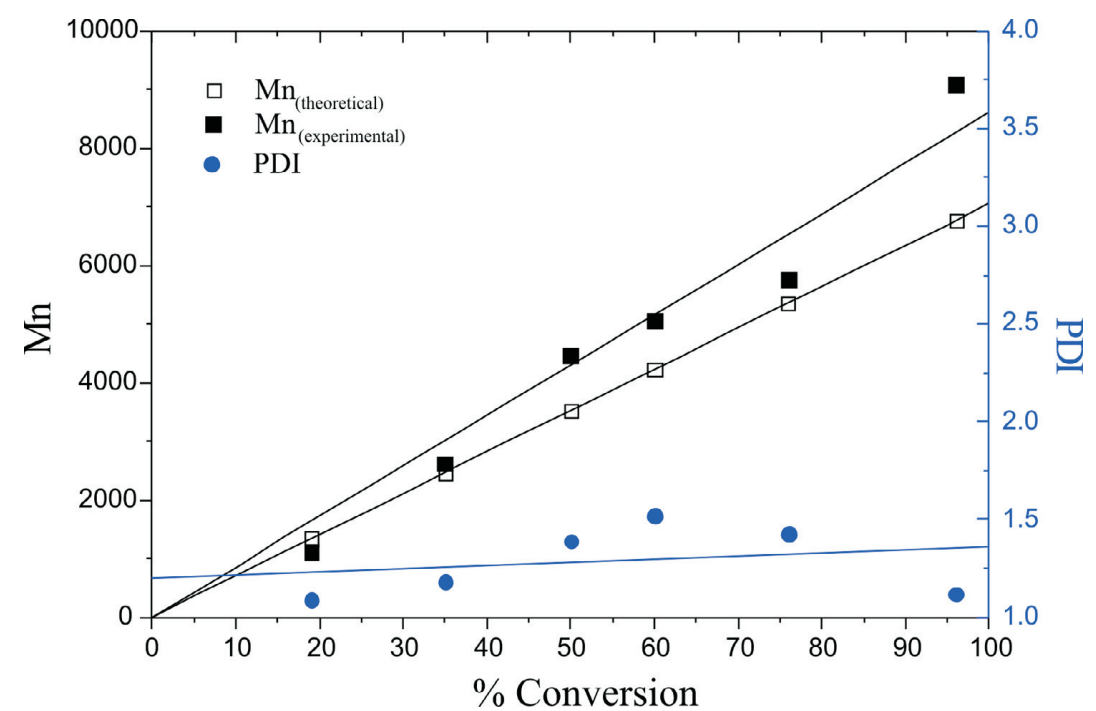

Figure 4 Plot of molecular weight and molecular weight distribution $v$ s conversion for the polymerization of L-LA by 1 .

version (Fig. 4). As an illustration, an increase in percentage conversion from $20 \%$ to $96 \%$ was marked by a concomitant increase in poly(L-LA) Mw from $1120 \mathrm{~g} \mathrm{~mol}^{-1}$ to $9081 \mathrm{~g} \mathrm{~mol}^{-1}$. The independence of molecular weight distribution on percentage conversion (Fig. 4) further augmented the living polymerization nature of 1.

We also studied the effect of monomer to catalyst ratio ([LA]/[1]) on polymer weight using catalyst 1 . Contrary to our expectations and literature reports, ${ }^{31,32}$ we observed a decrease in molecular weight with increase in $[\mathrm{LA}] /[1]$ ratio (Table 2, entries 8-10). For instance, an increase in $[\mathrm{LA}]_{0} /[\mathbf{1}]$ from 50 to 125 resulted in decrease of molecular weight from $4105 \mathrm{~g} \mathrm{~mol}^{-1}$ to $1593 \mathrm{~g} \mathrm{~mol}^{-1}$, respectively. Low catalyst loading is expected to result in increased chain growth per active site. Thus at this stage, we are unable to unambiguously account for the observed trend. All the polymers obtained exhibited relatively narrow molecular weight distributions (1.09-1.64) compared to the wide distributions of 2.00-3.96 we reported in the polymerization of $\varepsilon$-CL. ${ }^{20}$ The narrow PDIs coupled with the relatively high $\mathrm{Mw}$ observed in L-LA polymerization indicate absence/minimum transesterification reactions. ${ }^{33,34}$ However, low molecular weights of poly(D,L-LA) is consistent with the occurrence of intramolecular transesterification reactions. ${ }^{34}$ The narrow PDIs achieved for complexes 1-4 bearing acetate groups is in fact unusual as most acetate complexes give broad PDI in comparison to the alkoxide initiators. ${ }^{35}$

The nature of the metal centre also showed significant influence on the polymer molecular weight. Generally, zinc(II) complexes gave higher molecular weight PLAs than the analogous copper(II) complexes. For instance, poly(L-LA) molecular weights of $9081 \mathrm{~g} \mathrm{~mol}^{-1}$ and $2038 \mathrm{~g} \mathrm{~mol}^{-1}$ were obtained for complexes 1 and 2, respectively (Table 1, entries 5 and 6). Similar trends were observed in the polymerization of D,L-LA monomer. However, there was no significant steric influence on polymer molecular weight. Complexes $\mathbf{1}$ and $\mathbf{3}$ bearing methyl and phenyl groups on the pyrazolyl motif furnished molecular weights of $2381 \mathrm{~g} \mathrm{~mol}^{-1}$ and $2455 \mathrm{~g} \mathrm{~mol}^{-1}$, respectively (Table 1, entries 1 and 3).

\subsection{Microstructural Analyses of Polylactides}

Poly(D,L-LA) and poly(L-LA) stereochemistry and tacticity were determined by homonuclear decoupled ${ }^{1} \mathrm{H}\{\mathrm{H}\}$ NMR and ${ }^{13} \mathrm{C}$ NMR spectroscopy. Figure 5 represents the homonuclear decoupled ${ }^{1} \mathrm{H}$ NMR and ${ }^{13} \mathrm{C}$ NMR spectra of the methine regions

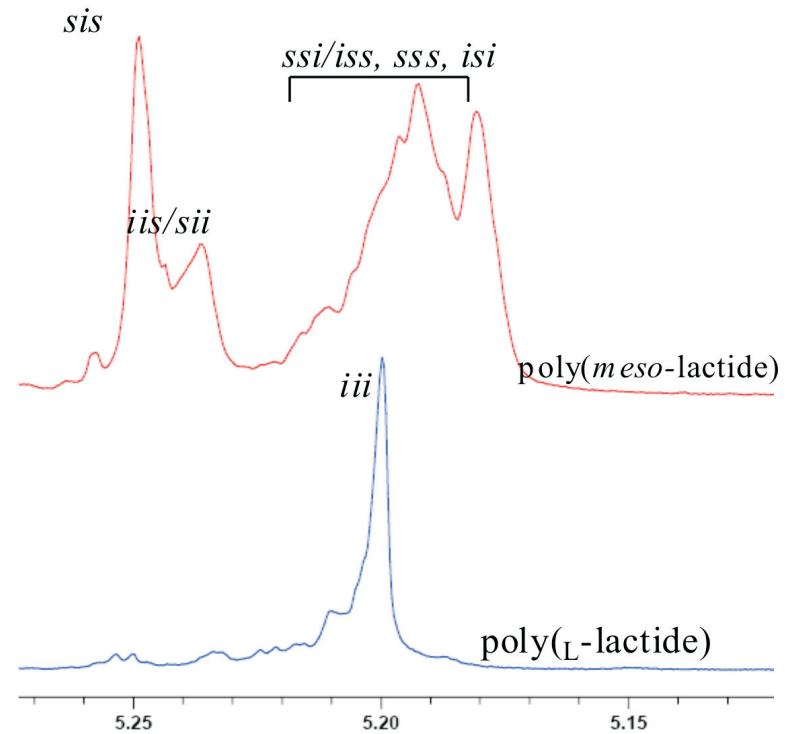

Figure 5 Homonuclear decoupled ${ }^{1} \mathrm{H}$ NMR spectra of the methine region of isotactic poly(L-LA) and atactic poly(D,L-LA) produced by 1 .

of the polymers, respectively. From the ${ }^{1} \mathrm{H}$ NMR spectra, it is evident that poly(L-LA) are predominantly isotactic while poly(-D,L-LA) are largely atactic (Scheme 2). ${ }^{36,37}{ }^{13} \mathrm{C}$ NMR spectra of both polymers were consistent with the interpretation of ${ }^{1} \mathrm{H}$ NMR data. ${ }^{38}$ Production of atactic poly(D,L-LA) thus demonstrates lack of control of polymer stereoregularity by $\mathbf{1}$. This could be attributed to the absence of chirality in $\mathbf{1}$ as was demonstrated by optical N-heterocyclic carbene catalysts in the polymerization of D,L-LA to give predominantly heterotactic polymers. ${ }^{39}$ In addition, Ovitt and Coates have reported the use of chiral aluminium and yttrium alkoxide to produce heterotactic and syndiotactic PLAs from meso-lactide, respectively. ${ }^{40}$

The ring-opening polymerization of LA by metal-based catalysts is likely to proceed either via coordination-insertion mechanism (CIM) or activated-monomer mechanism (AMM). ${ }^{7}$ In the CIM route, the polymer end chain bears the nucleophile (acetate in this case) on one end and the metal centre on the other end. However, chain transfer agents (water or alcohols) in the system might promote hydrolysis of the metal end to form an -OR end group. ${ }^{41}$ Polymerization through activatedmonomer mechanism results in polymers bearing OR as end groups from an external nucleophiles (water or alcohols). ${ }^{42}$ To 


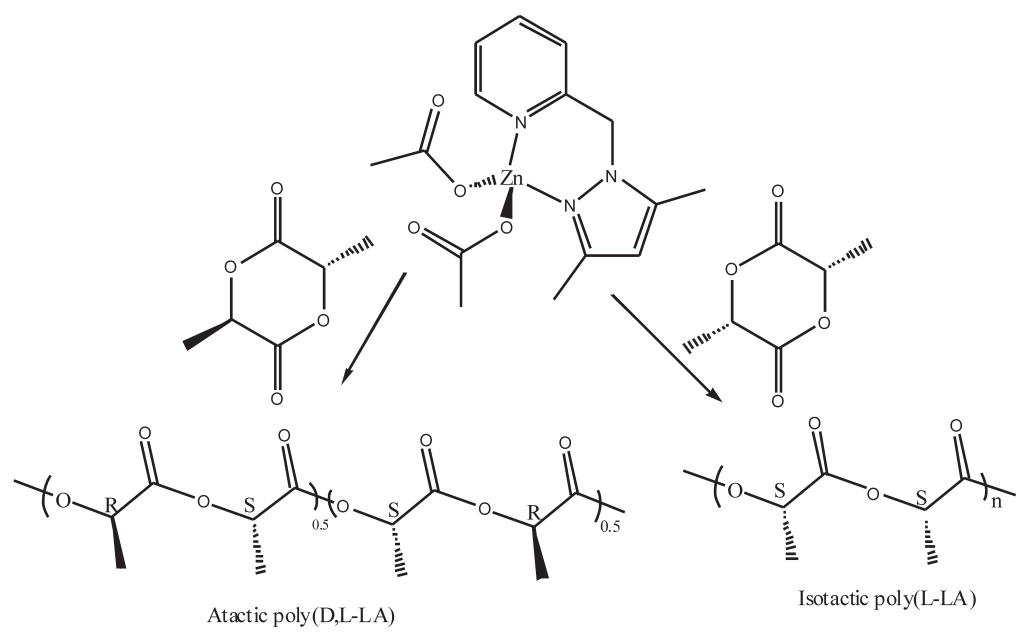

Scheme 2

Mechanism of LA polymerization.

establish the mechanism of lactide polymerization by $1,{ }^{1} \mathrm{H} N \mathrm{NR}$ and ESI-MS spectra of the polymers obtained were analyzed. ${ }^{1} \mathrm{H}$ NMR spectra of all the polymers revealed the absence of acetate methyl signals at about 2.00 ppm (Fig. 6). Similarly, no signals associated with ligand moiety in the complexes were observed. These observations are consistent with activated monomer mechanism. However, the linear dependency of polymerization kinetics with respect to [1] (Figs 2 and 3) strongly agree with coordination-insertion mechanism. Analyses of the ESI-MS spectra of poly(D,L-LA) exhibited signals corresponding to $\mathrm{HO}\left(\mathrm{C}_{6} \mathrm{H}_{8} \mathrm{O}_{4}\right)_{n} \mathrm{HNa}^{+}$(Fig. 7). The presence of $-\mathrm{OH}$ end group could arise from adventitious water molecules. The $-\mathrm{OH}$ end groups could originate from adventitious water molecules that are capable of initiating hydrolysis of the polymer chain. These results are in agreement with those reported by Pilone et al. ${ }^{43}$ and Bourissou et al. ${ }^{34}$ in which water molecules hydrolyzed the polymer end chains. From these data, the polymerization reactions by complexes 1-4 can thus be said to proceed through coordination insertion mechanism followed by hydrolysis of the acetate and complex end groups.

\section{Conclusions}

In summary, we have successfully shown that (pyrazol-1- ylmethyl)pyridine $\mathrm{Zn}(\mathrm{II})$ and $\mathrm{Cu}(\mathrm{II})$ complexes 1-4 formed active initiators for the ring-opening polymerization of D,L-LA and L-LA monomers. Both the nature of the metal atom and monomer influenced the catalytic behaviour of these compounds with Zn(II) complexes and L-LA displaying higher catalytic activities. The kinetics of the polymerization reactions were pseudo-first-order and second-order with respect to monomer and initiator 1 , respectively. The polymerization reactions have been established to proceed through coordination insertion mechanism followed by hydrolysis of the acetate and complex end groups by water molecules. While poly(L-LA) were predominantly isoactactic, poly(D,L-LA) were mainly atactic indicating lack of control of polymer microstructure. Our current focus is on the design of catalyst systems that contain alkoxide initiating groups and stereogenic centres within the ligand framework to impart better control of polymer stereochemistry.

\section{Supplementary Material}

Supplementary Fig. S1 represents graphs of percentage conversions of D,L-LA and L-LA to PLA for catalysts 1-4 while Fig. S2 is a plot of $\left.\ln [\mathrm{LA}]_{0} / \mathrm{LA}\right]_{\mathrm{t}}$ vs time for $\mathbf{1}$ using different catalyst concentrations at constant monomer concentration of 0.01 mmol. GPC chromatograms for selected polylactides obtained

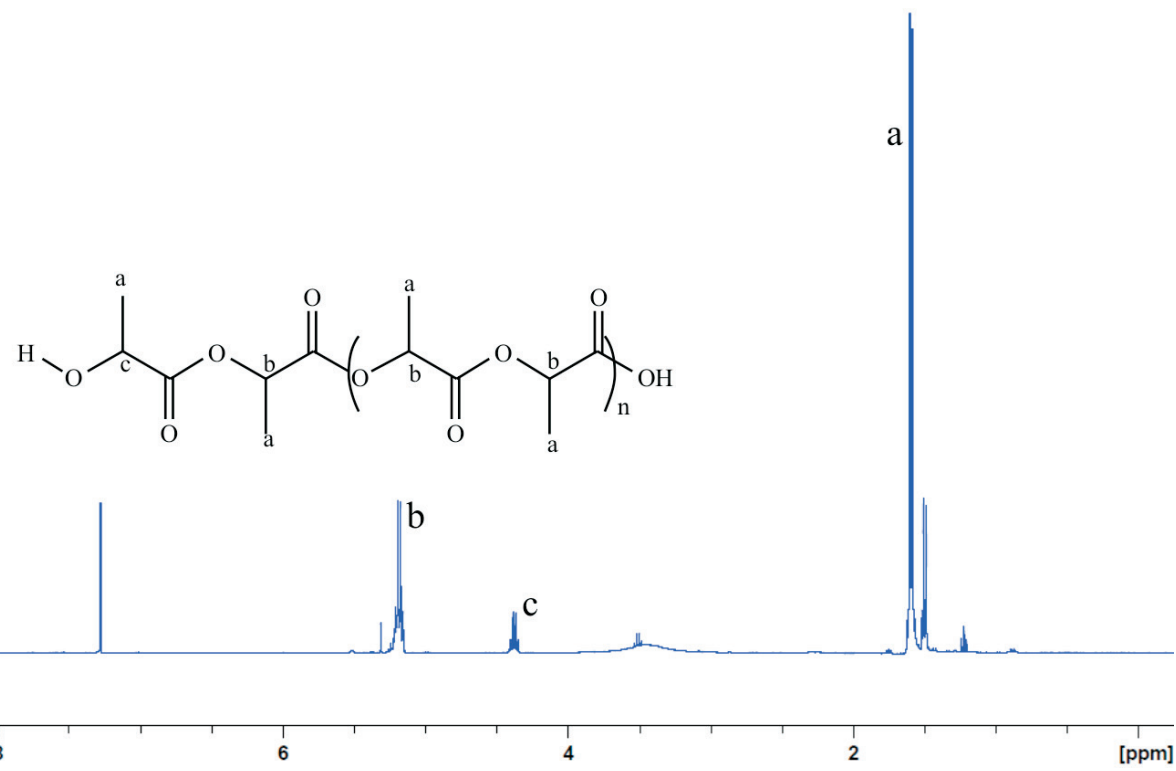

Figure $6{ }^{1} \mathrm{H}$ NMR spectrum of poly(D,L-LA) produced by 1 corresponding to $95 \%$ conversion. 


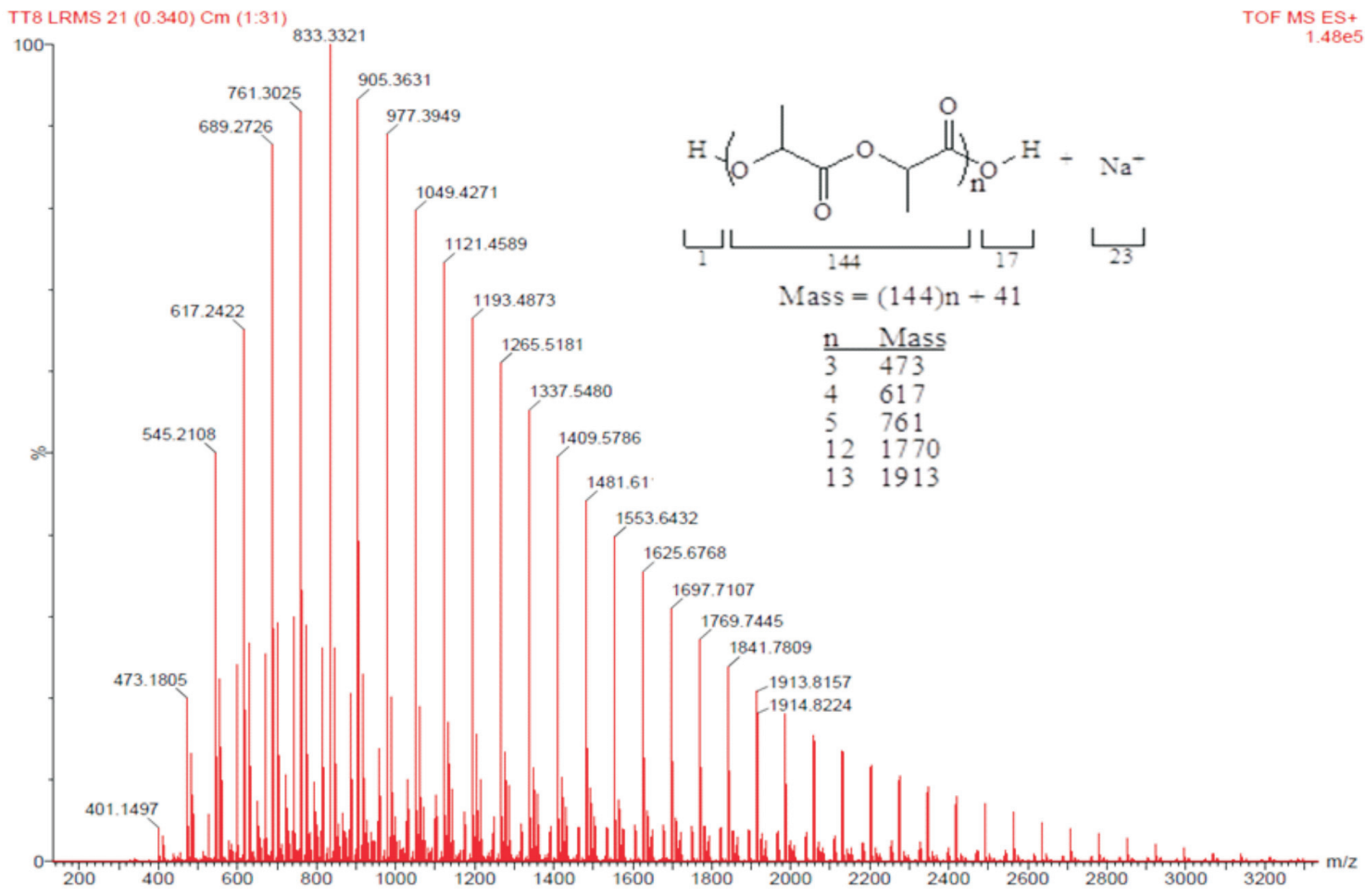

Figure 7 ESI spectrum of crude poly(D,L-LA) prepared from $\mathbf{1}$ for $9 \mathrm{~h}$ corresponding to $95 \%$ conversion.

are shown in Figs S3-S4. Figure S5 depicts the ESI-MS spectrum of crude poly(L-LA) obtained from 1.

\section{Acknowledgements}

The authors would like to thank University of KwaZulu-Natal for financial support.

\section{References}

1 A.P. Gupta and V. Kumar, Eur. Polym J., 2007, 43, 4053-4073.

2 M. Vivas, and J. Contreras, Eur. Polym J., 2003, 39, 43-56.

3 F. Majoumo-Mbe, E. Smolensky, P. Lonnecke, D. Spasser, M.S. Eisen and E. Hey-Hawkins, J. Mol. Catal. A: Chem., 2005, 240, 91-98.

4 L. Azor, C. Bailly, L. Brelot, M. Henry, P. Mobian and S. Dagorne, Inorg. Chem., 2012, 51, 10876-10883.

5 H. Tian, Z. Tang, X. Zhuang, X. Chen and X. Jing, Prog. Polym. Sci., $2012,37,237-238$.

6 C.S. Joseph, K.V.H, Prashanth, N.K. Rastogi, A.R. Indiramma, S.Y. Reddy, K.S.M.S. Raghavarao, Food Bioprocess Technol., 2011, 4 1179-1185. (b) M. Minami, S. Kozaki, US patent 2003/6531615 B2, 2003. (c) B.D. Ulery, L.S. Nair and C.T. Laurencin, J. Polym. Sci., Part B: Polym. Phys., 2011, 49, 832-864. (d) J.C. Middleton, A.J. Tipton, Biomaterials 2000, 21, 8,

7 J. Wu, T.-L. Yu, C.-T. Chen and C-C. Lin, Coord. Chem. Rev., 2006, 250 602-626.o

8 Y. Miao, Y. Phuphuak, C. Rousseau, T. Bousquet, A. Mortreux, S. Chirachanchai and P. Zinck, J. Polym. Sci. Part A: Polym. Chem., 2013, 51, 2279-2287.

9 S. Matsumura, Macromol. Biosci., 2002, 2, 105-126.

10 J. Cayuela, V. Bounor-Legaré, P. Cassagnau and A. Michel, Macromolecules, 2006, 39, 1338-1346.

11 B.J. O'Keefe, M.A. Hillmyer and W.B. Tolman, J. Chem. Soc. Dalton Trans., 2001, 2215-2224.

12 K.M. Stridsberg, M. Ryner and A.-C. Albertsson, Adv. Polym. Sci., 2002, 157, 41-65.

13 H. Du, X. Pang, H. Yu, X. Zhuang, X. Chen, D. Cui, X. Wang and X. Jing, Macromolecules, 2007, 40, 1904-1913.

14 (a) A.C. Albertsson and I.K. Varma, Adv. Polymer Sci., 2002, 157, 1-40; (b) US Patent 5258 488, 1993.

15 M.J. Stanford, P. Andrew and P. Dove, Chem. Soc. Rev., 2010, 39, 486-496.
16 M.H. Chisholm, J.C. Gallucci and K. Phomphrai, Inorg. Chem., 2004, 43, 6717-6725.

17 B. J. Ireland, C.A. Wheaton and P.G. Hayes, Organometallics, 2010, 29, 1079-1084.

18 C.-Y. Sung, C.-Y. Li, J.-K. Su, T.-Y. Chen, C.-H. Lin and B.-T. Ko, Dalton Trans., 2012, 41, 953-961.

19 V. Poirier, T. Roisnel,J.-F. Carpentier and Y. Sarazin, Dalton Trans., 2011, 40, 523-534.

20 S.O. Ojwach, T.T. Okemwa, N.W. Attandoh and B. Omondi, Dalton Trans., 2013, 42, 10735-10745.

21 M. Bouyahyi, N. Ajellal, E. Kirillov, C.M. Thomas and J.F. Carpentier, Chem. Eur. J., 2011, 17, 1872-1883.

22 M. Labet and W. Thielemans, Chem. Soc. Rev., 2009, 38, 3484-3504.

23 J-C. Buffet,J.P. Davin, T.P. Spaniol and J. Okuda, New J. Chem., 2011, 35, 2253-2257.

24 C. K. Williams, L.E. Breyfogle, S. Kyung Choi, W. Nam, V. G. Young Jr, M.A. Hillmyer and W.B. Tolman, J. Am. Chem. Soc., 2003, 125, 11350-11359.

25 H.-Y. Chen, B.-H. Huang and C.-C. Lin, Macromolecule, 2005, 38, 5400-5405.

26 H. Sun, J.S. Ritch and P.G. Hayes, Dalton Trans., 2012, 41, 3701-3713.

27 Z. Zhong, P.J. Dijkstra and J. Feijen, J. Am. Chem. Soc., 2003, 125, $11291-11298$

28 Y. Huang, W. Wang, C.C. Lin, M.P. Blake, L. Clark, A.D. Schwarz and P. Mountford, Dalton Trans., 2013, 42, 9313-9324.

29 C.M. Silvernail, L.Y. Yao, L.M.R. Hill, M.A. Hillmyer and W.B. Tolman, Inorg. Chem., 2007, 46, 6565-6574.

30 J.P. Davin, J.-C. Buffet, T.P. Spaniol and J. Okuda, Dalton Trans., 2012, 41, 12612-12618.

31 W.M. Stevels, M.J. Ankone, P.J. Dijkstra and J. Feijen, Macromolecules, 1996, 29, 6132-6138.

32 S. J. MClain, T.M. Ford and N.E. Drysdale, Polym. Prepr. (Am. Chem. Soc. Div. Polym. Chem.) 1992, 33, 463-464.

33 B.M. Chamberlain, B.A. Jazdzewski, M. Pink, M.A. Hillmyer and W.B. Tolman, Macromolecules, 2000, 33, 3970-3977.

34 D. Bourissou, B. Martin-Vaca, A. Dumitrescu, M. Graullier and F. Lacombe, Macromolecules, 2005, 38, 9993-9998.

35 Chamberlain, B.M., B.A. Jazdzewski, M. Cheng, D.R. Moore, T.M. Ovitt, E.B. Lobkovsky and G.W. Coates, J. Am. Chem. Soc., 2001, 123, 3229-3238. 
36 K.A.M. Thakur, R.T. Kean, M.T. Zell, B.E. Padden and E.J. Munson, Chem. Commun., 1998, 1913-1914.

37 K.A.M. Thakur, R.T. Kean, E.S. Hall, J.J. Kolstad and E.J. Munson, Macromolecules, 1998, 31, 1487-1494.

38 W. Jiang, W. Huang, N. Cheng, Y. Qi, X. Zong, H. Li and Q. Zhang, Polymer, 2012, 53, 5476-5479.

39 A.P. Dove, H. Li, R.C. Pratt, B.G.G. Lohmeijer, D.A. Culkin, R.M. Waymouth and J.L. Hedrick, Chem. Commun., 2006, 27, 2881-2883.
40 T.M. Ovitt and G.W. Coates, J. Polym. Sci., Part A: Polym. Chem., 2000, 38, 4686-4692.

41 G. Odian, Principles of Polymerization, 3rd edn., John Wiley \& Sons, New York, 1991, pp. 550-551.

42 N. Ajellal, J.-F. Carpentier, C. Guillaume, S.M. Guillaume, M. Helou, V. Poirier, Y. Sarazin and A. Trifonov, Dalton Trans., 2010, 39, 8363-8376.

43 A. Pilone, M. Lamberti, M. Mazzeo, S. Milione and C. Pellecchia, Dalton Trans., 2013, 42, 13036-13047. 


\section{Ring-Opening Polymerization of Lactides By (Pyrazol-1-ylmethyl)pyridine}

\section{$\mathrm{Cu}(\mathrm{II})$ and $\mathrm{Zn}$ (II) Complexes: Kinetics, Mechanism and Tacticity Studies}

Stephen O. Ojwach* and Thembisile P. Zaca

School of Chemistry and Physics, University of KwaZulu-Natal, Pietermaritzburg Campus,

Private Bag X01 Scottsville, 3209, South Africa.

\section{Supplementary information}

Table of contents

Figure

Figure S1: Plots of percentage conversion of polymerization reactions of D,L-LA 2 and L-LA lactide monomers by complexes 1-4

Figure S2: Plot of $\ln [\mathrm{D}, \mathrm{L}-\mathrm{LA}]_{0} /[\mathrm{D}, \mathrm{L}-\mathrm{LA}]_{\mathrm{t}}$ vs time at different $[\mathrm{D}, \mathrm{L}-\mathrm{LA}]_{0} /[\mathbf{1}]$ at constant $[\mathrm{D}, \mathrm{L}-\mathrm{LA}]$ monomer concentration of $0.01 \mathrm{mmol}$.

Figure S3: GPC chromatogram of poly(D,L-LA) obtained from complex 1, at M/I 4 of 50 , time $9 \mathrm{~h}(95 \%)$.

Figure S4: GPC chromatogram of poly(L-LA) produced by complex 1, at M/I of 50, 4 time $23 \mathrm{~h}(95 \%)$.

Figure S5: ESI spectrum of crude poly(L-LA) obtained from 1 at $110{ }^{\circ} \mathrm{C}$, time, $9 \mathrm{~h}$ $(95 \%)$. Mass fragments agree with the presence of $\mathrm{OH}$ functionality and $\mathrm{Na}^{+}$cation.

For example, $\mathrm{m} / \mathrm{z}=761=5(144)+41$. 

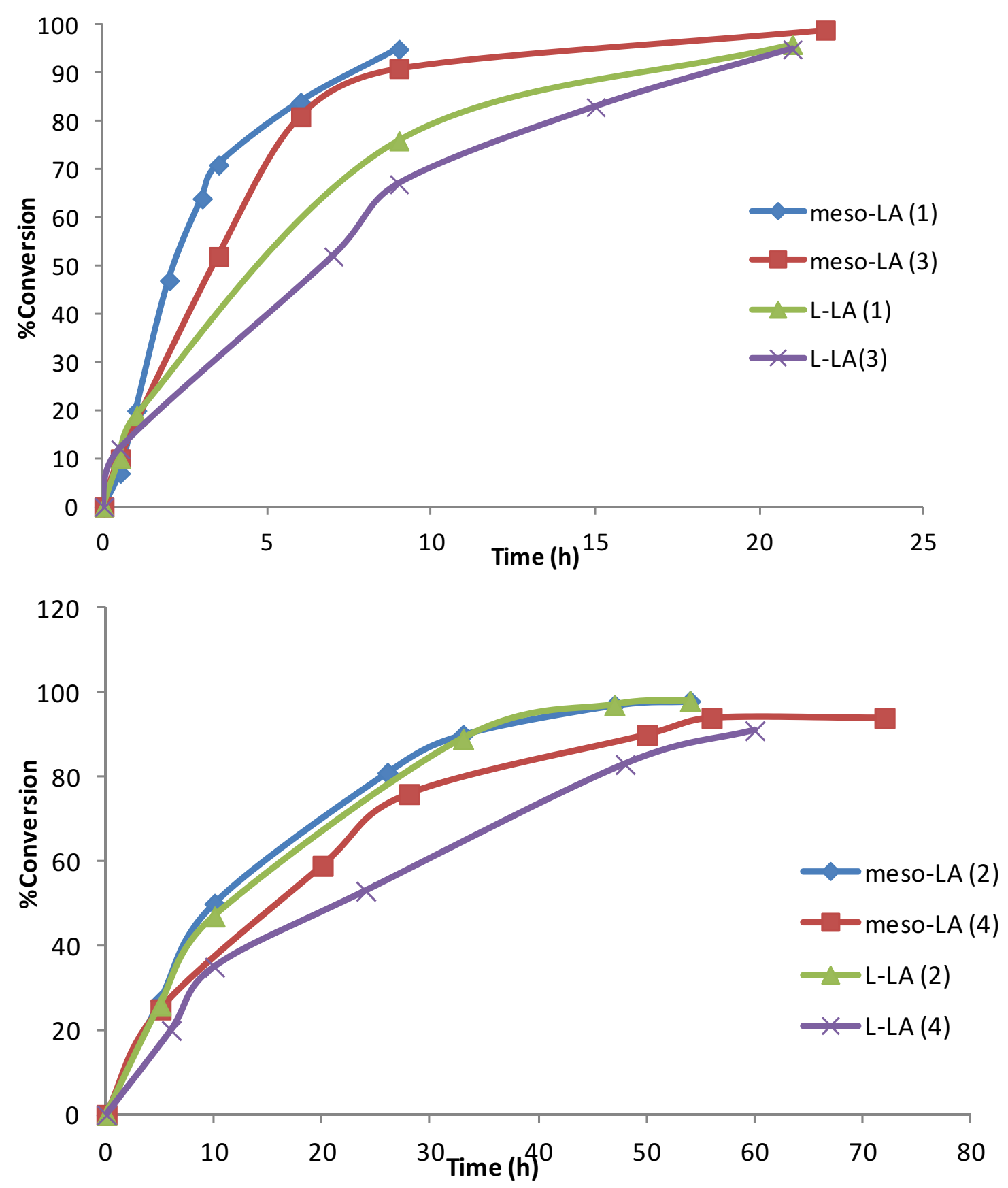

Figure S1: Plots of percentage conversion of polymerization reactions of D,L-LA and L-LA lactide monomers by complexes 1-4 


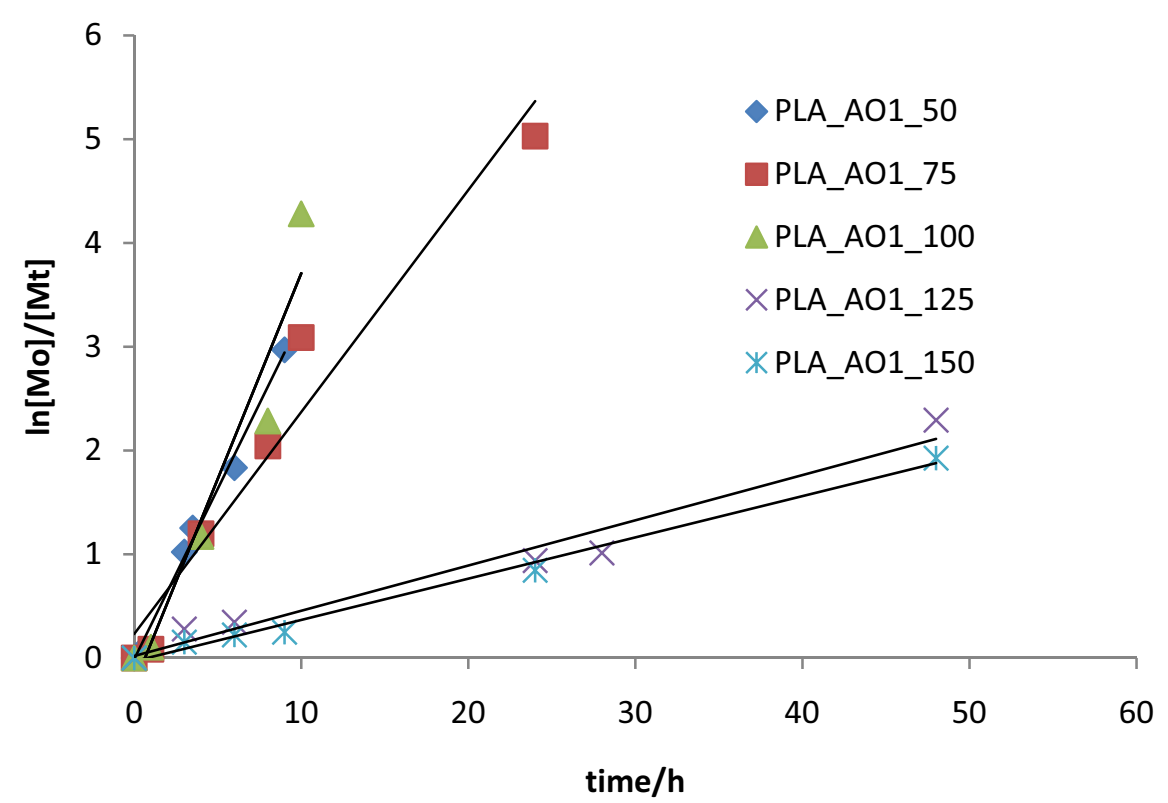

Figure S2: Plot of $\ln [\mathrm{D}, \mathrm{L}-\mathrm{LA}]_{0} /[\mathrm{D}, \mathrm{L}-\mathrm{LA}]_{\mathrm{t}}$ vs time at different $\left.[\mathrm{D}, \mathrm{L}-\mathrm{LA}]_{0} /[1]\right]$ at constant $[\mathrm{D}, \mathrm{L}-\mathrm{LA}]$ monomer concentration of $0.01 \mathrm{mmol}$. 
Broad Unknown Relative Chromatogram

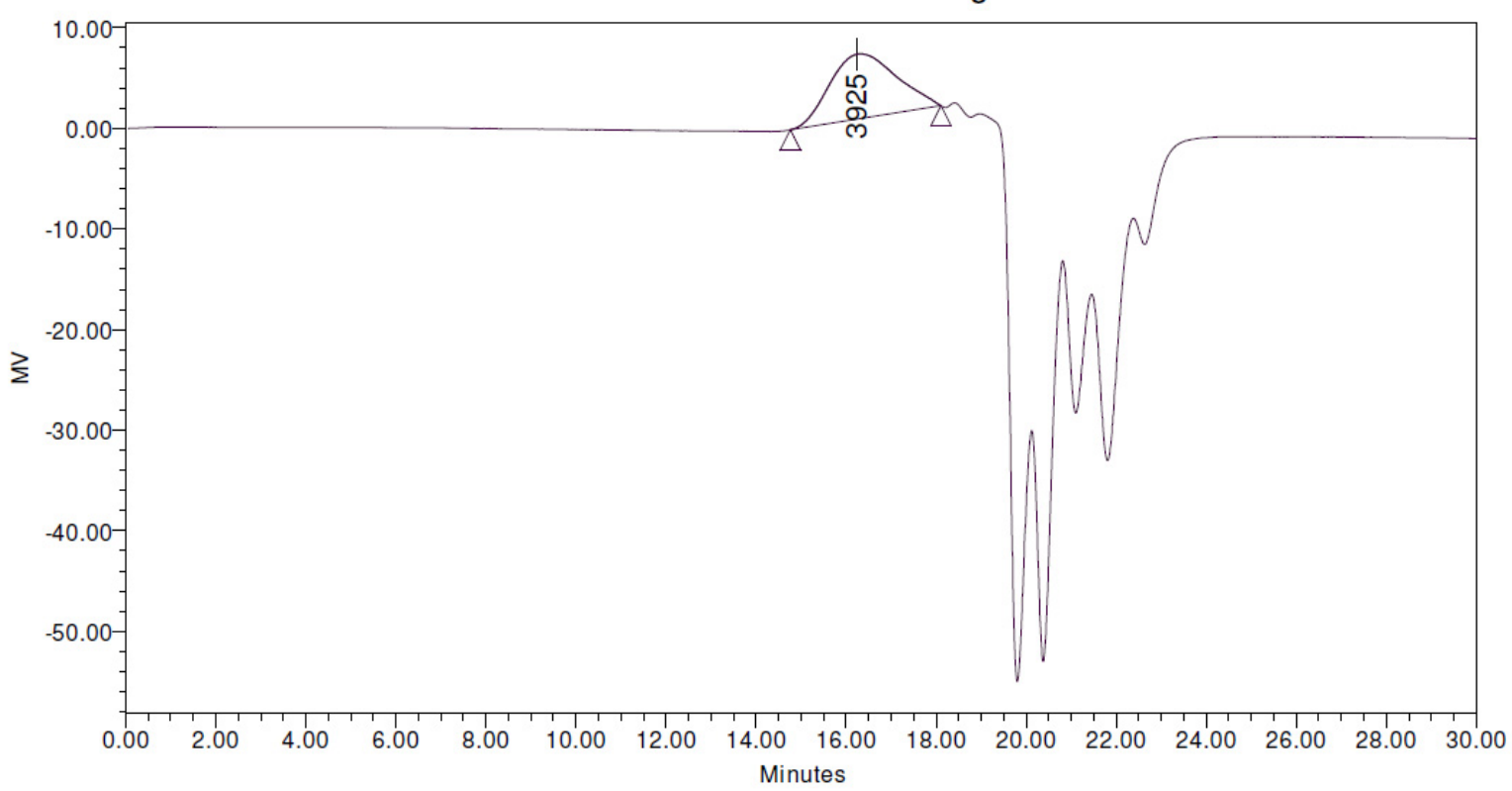

Figure S3: GPC chromatogram of poly(D,L-LA) obtained from complex 1, at $\mathrm{M} / \mathrm{I}$ of 50, time $9 \mathrm{~h}(95 \%)$.

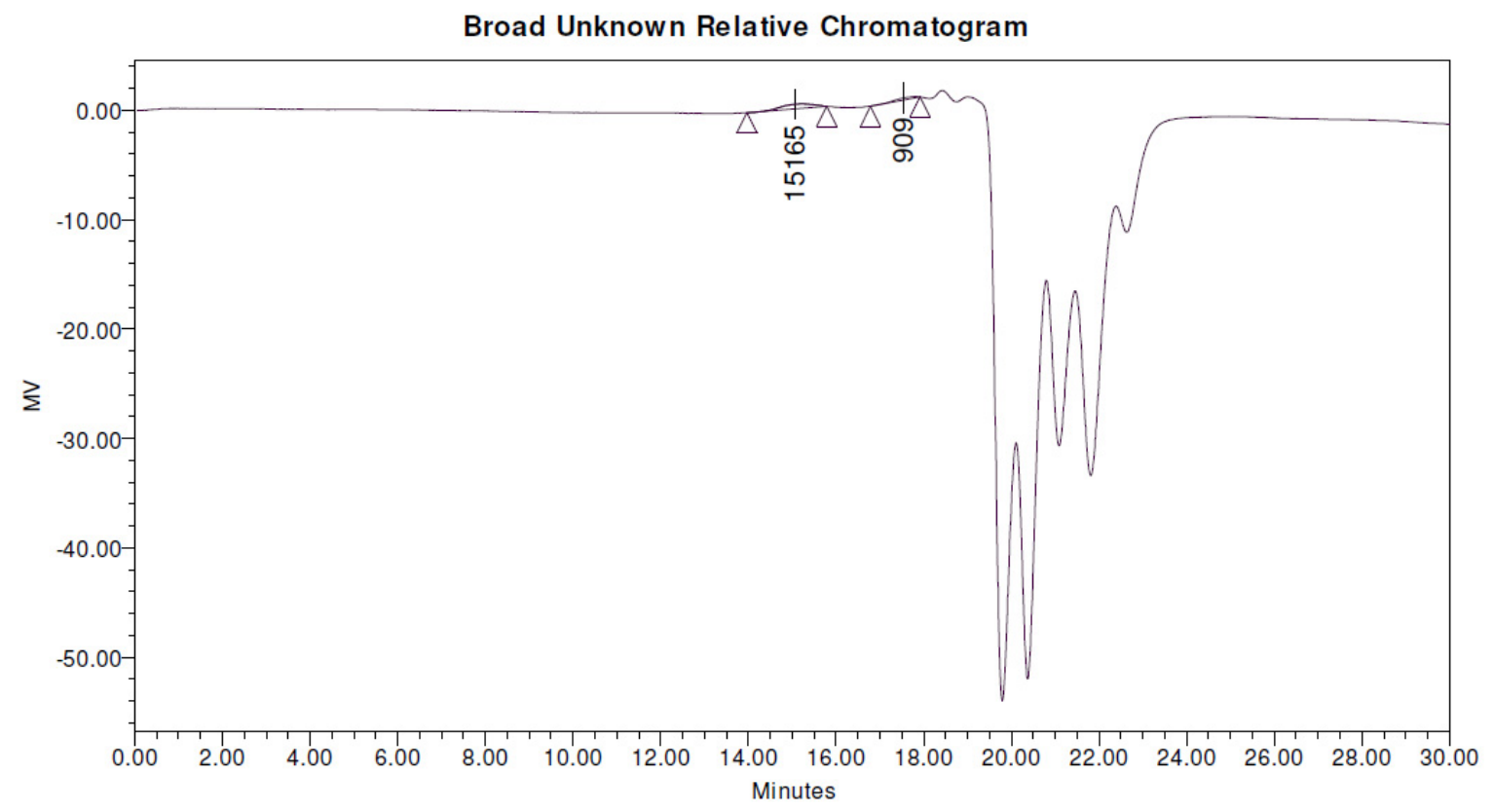

Figure S4: GPC chromatogram of poly(L-LA) produced by complex 1, at M/I of 50, time 23 h $(95 \%)$. 


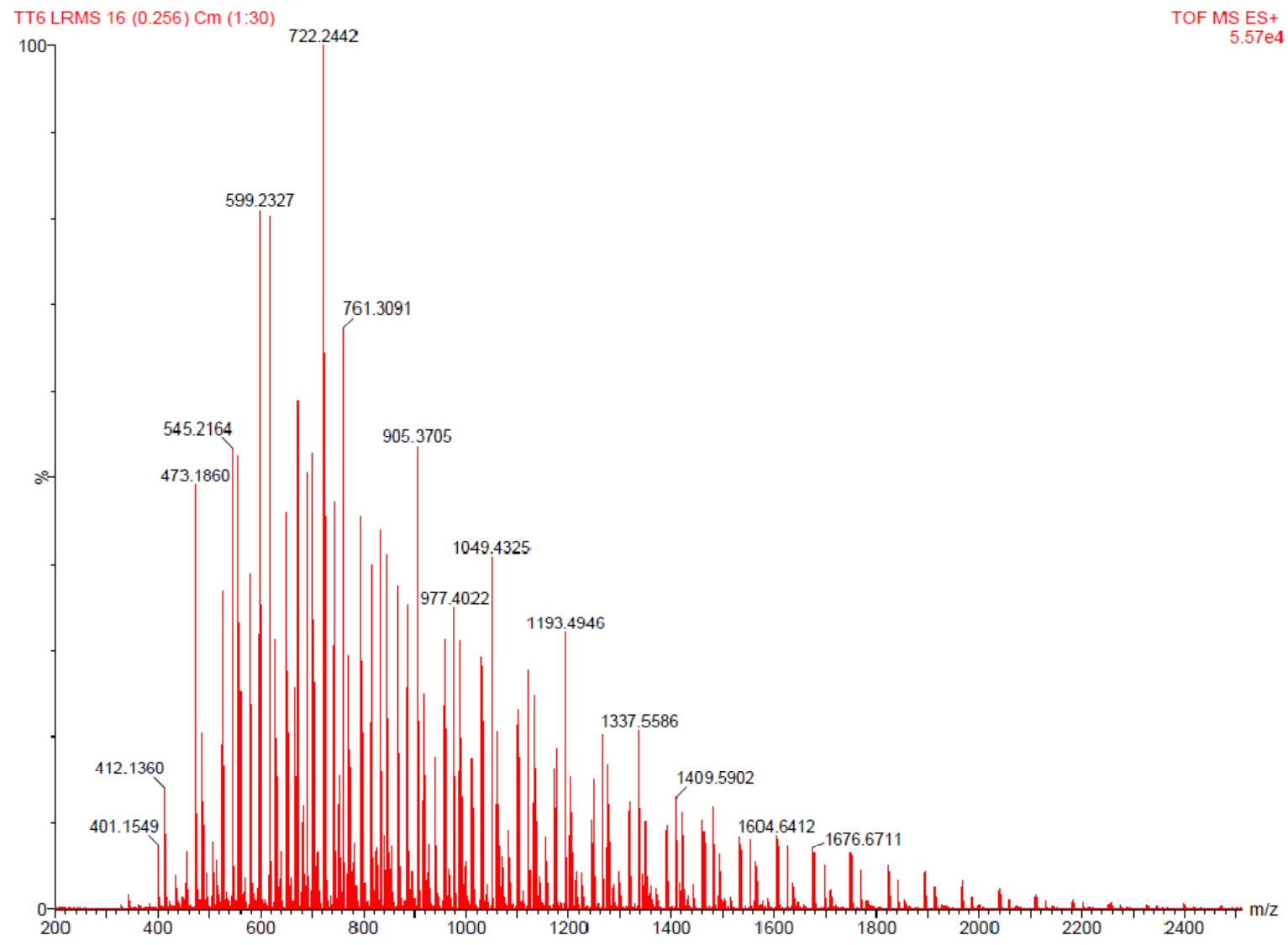

Figure S5: ESI spectrum of crude poly(L-LA) obtained from 1 at $110{ }^{\circ} \mathrm{C}$, time, $9 \mathrm{~h}(95 \%)$. Mass fragments agree with the presence of $\mathrm{OH}$ functionality and $\mathrm{Na}^{+}$cation. For example, $\mathrm{m} / \mathrm{z}=761=5(144)+41$. 